
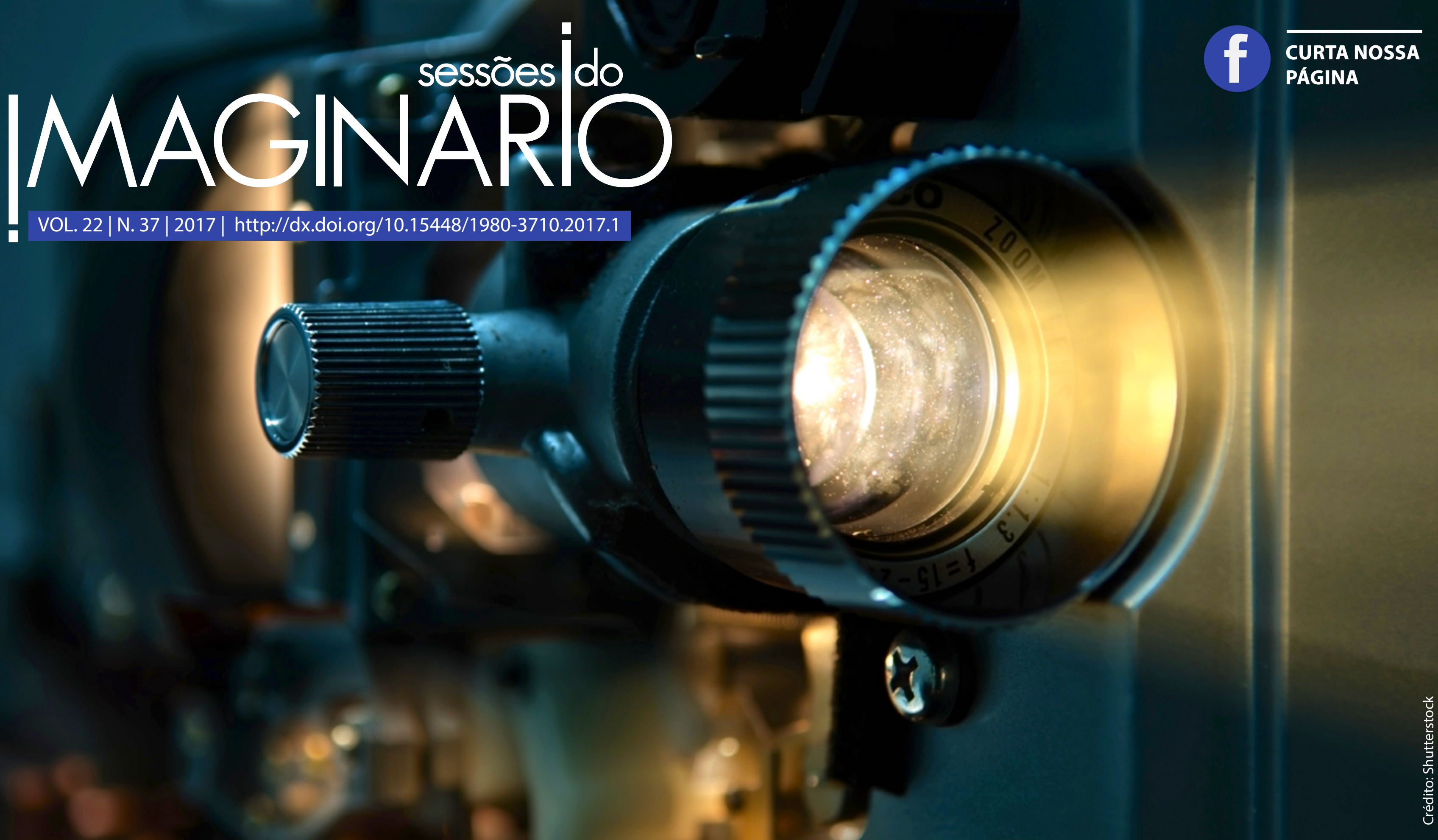

A Comunicação Móvel e Ubíqua do Instagram

Eduardo Campos Pellanda e Melissa Streck
O choque do real em Azul é a cor mais quente

Otacílio Amaral Filho, Sérgio do Espírito Santo Ferreira Júnior e Tarcízio Macedo
A luta de classes em Que Horas ela Volta?

Mayara Luma Assmar Correia Maia Lobato 


\section{Funny Ha Ha: causalidades fragmentadas}

\section{Funny Ha Ha: fragmented causalities}

\section{Carlos Pernisa Júnior ${ }^{1} \boldsymbol{\jmath}$}

Luiz Otávio Vieira Pereira ${ }^{2} \square$

\section{Resumo}

O objetivo do artigo é realizar uma análise do filme Funny $\mathrm{Ha} \mathrm{Ha}$ (2002), dirigido por Andrew Bujalski e responsável por inaugurar o movimento mumblecore nos EUA, cuja diegese extrai sua verdade de uma imagem incompleta, de uma temática que não se revela e de um gênero que, a todo o momento, se esconde. Nesse sentido, tendo em vista a articulação do real em Hal Fostere os regimes deidentificação da arte propostos por Jacques Rancière, a ideia do estudo é reconhecer nos tempos mortos construídos por Bujalski a noção traumática da incomunicabilidade e ao mesmo tempo entender a desconstrução narrativa que valoriza o fragmento em detrimento de qualquer hierarquia representacional.

\section{Palavras-chave}

Cinema; regime estético; efeitos de real; mumblecore.

\section{Abstract}

The purpose of the article is to perform an analysis of the movie Funny $\mathrm{Ha} \mathrm{Ha}$ (2002), directed by Andrew Bujalski and responsible for inaugurating the mumblecore movement in the US, whose diegesis extracts its truth from an incomplete image, from a thematic that does not reveal itself and of a genre that every moment hides itself. In this sense, considering the articulation of the real in Hal Foster and the art's identification regimes proposed by Jacques Rancière, the idea of the study is to recognize in Bujalski's constructed dead times the traumatic notion of incommunicability and, at the same time, to understand the narrative deconstruction that appreciate the fragment instead of any representational hierarchy.

\section{Keywords}

Cinema; esthetic regime; real effects; mumblecore.

94 PORTO ALEGRE | v. 22 | n. 37| 2017 | pp. 94-101 DOI: http://dx.doi.org /10.15448/1980-3710.2017.1.26218 Sessões do Imaginário 


\section{Introdução}

No início dos anos 2000, a rotina dos festivais de cinema independente dos Estados Unidos foi assolada por uma série de filmes que, apesar de esteticamente desiguais, traziam embutidos um esforço comum no retrato naturalista da vida cotidiana ao mesmo tempo em que projetavam uma noção incômoda em torno de uma metalinguística crise de autodefinição. Se por um lado, estes cineastas tinham consciência do cenário de ruptura que engendravam, sobretudo em virtude dos materiais tecnológicos e do escasso orçamento que dispunham, por outro, o exercício se valia justamente pela dúvida diante da câmera e pelo modo ambíguo como a realidade era articulada.

Diante de um movimento cinematográfico em suspensão, a crítica Amy Taubin, em um artigo para a Film Comment, tentando demarcar as bases para um grupo tão heterogêneo, passou a relacionar os novos diretores à geração neo-slacker, que tem em Richard Linklater e Kevin Smith seus representantes mais importantes. Já Ray Pride, colaborador do blog indieWIRE, um dos mais relevantes na cobertura independente sobre cinema, cunhou a expressão slackavettes, em clara referência tanto ao filme Slacker (Richard Linklater, 1991) de Linklater, quanto ao cinema de John Cassavetes. Desta maneira, ao tatear as possibilidades e influências desta geração de cineastas, a imprensa norte-americana logo se sentiu autorizada em clivar um novo nicho a ser explorado: surgia assim, à revelia de seus membros, o movimento mumblecore.

Tendo em vista o recorte desta realidade, e através de uma análise estética e narrativa do filme Funny $\mathrm{Ha} \mathrm{Ha}$ (Andrew Bujalski, 2002), o presente artigo irá se debruçar sobre a construção imagética da obra em questão para pensar como o prolongamento dos tem- pos mortos, a apatia e a indecisão narrativa, a repetição de cenas aparentemente banais e a percepção de um todo que nunca se mostra suficiente, são capazes de despertar no espectador afetos traumáticos e uma abertura incômoda ao real. Dentro desta perspectiva, o estudo irá, também, traçar as implicações destes efeitos de realidade que, ao destituir a ação de sua estrutura clássica de causa e efeito, introduz uma imagem preocupada menos em emular emoções do que construir microeventos. Nesse sentido, ajudando a balizar a pesquisa, o diálogo entre autores como Hal Foster e Jacques Rancière é capaz de iluminar o cultivo de uma nova noção de verossimilhança que transforma o real em uma experiência ao mesmo tempo pré-significante e opaca.

Funny $\mathrm{Ha} \mathrm{Ha}$ é o primeiro longa-metragem dirigido por Andrew Bujalski, que também assina o roteiro, edita e atua no filme. Considerado precursor do movimento mumblecore, a obra, apesar de finalizada em 2002, só começou a ser distribuída em 2005, quando conseguiu se internacionalizar no intercâmbio com outros diretores que partilhavam de uma mesma sensibilidade estética. Apesar de lançar as bases para toda uma nova geração de cineastas, que somente conseguiram romper a barreira da invisibilidade a partir da democracia e da desoneração que as mídias digitais inauguraram, Funny $\mathrm{Ha} \mathrm{Ha}$, assim como Mutual Appreciation (2005), o filme seguinte de Bujalski, foi filmado em película 16 $\mathrm{mm}$, um recurso que o conecta antes à longa história do cinema independente.

Vencedor do prêmio Someone to Watch, no Independent Spirit Awards, em 2004, e eleito, no mesmo ano, o melhor longa-metragem, no Black Point Film Festival, o filme trabalha temas caros à geração mumblecore, como os sentimentos de inadequação e desconforto perante a realidade, a incomunicabilidade interpessoal, a repetição imagética e a dilatação temporal. 0 diretor dispensa ainda as grandes catarses ou os diálogos espirituosos típicos da narrativa cinematográfica clássica. Acompanhando a protagonista Marnie (Kate Dollenmayer), enquanto esta tenta arranjar um emprego temporário ao mesmo tempo em que administra o consumo diário de bebida alcoólica entre um flerte e outro com seu amigo de colégio, Alex (Christian Rudder), o espectador é conduzido, a todo o momento, pelas dúvidas de um movimento em sua fase embrionária que, ao mesmo tempo, não se furta em contratá-las com as certezas consolidadas pela narrativa cinematográfica ao longo do tempo.

\section{Melancolia das banalidades}

As primeiras cenas de Funny $\mathrm{Ha} \mathrm{Ha}$ já ditam a tônica de todo o projeto. Sem conexão entre si, as elipses quebram com qualquer expectativa em relação à progressão narrativa. Logo no início do longa-metragem, a protagonista, Marnie, aparece bêbada em um estúdio de tatuagem. Considerando uma atitude legal trazer inscrições de tinta na pele, ela se sente disposta a ser tatuada, embora não tenha sequer uma ideia de desenho definida, mesmo desconfiando de sua predileção por motivos célticos. Na cena seguinte, a trama sobre álcool e tatuagens é abandonada para apresentar o drama de uma jovem desempregada, recentemente demitida por ter ousado sugerir um aumento salarial. Por fim, no próximo corte, o filme já investe em outro tom narrativo ao buscar um flerte às avessas com um gênero tipicamente norte-americano: a comédia romântica, pincelando com cargas platônicas a relação que a personagem em questão mantém com seu antigo amigo de colégio, Alex. 
Diante de cenas que mais parecem curtas-metragens, alinhavados arbitrariamente em sequência do que propriamente excertos de um universo coeso, diálogos que apesar de perscrutarem os problemas jamais conseguem abordá-los claramente, uma espontaneidade naturalista que rompe com os clichês de filmes sobre jovens problemáticos, e uma verborragia que esgota a ação, ao mesmo tempo em que dilui os simbolismos de uma realidade dada, é preciso, antes de tudo, delimitar as intenções aqui sugeridas por Andrew Bujalski.

Apesar de haver um grande esforço por parte da crítica em aproximar a construção diegética de Bujalski de diretores como Eric Rohmer, talvez por um desenvolvimento digressivo que se recusa a lidar com as tensões narrativas; ou John Cassavetes, em uma confusão que tende a equiparar suportes técnicos e desenvolvimento estético, o fluxo das imagens em Funny $\mathrm{Ha} \mathrm{Ha}$ passa ao largo das comparações fáceis. Cada plano do filme contribui para direcionar a obra para um estado de não-ação, como se a mise-en-scène e o improviso dos atores, mesmo percebendo um problema, preferissem deixar os conflitos esvanecerem em uma total atmosfera de apatia e imobilidade. Nesse sentido, citando o crítico Gerald Peary, ex-colunista e crítico do periódico Boston Phoenix, Alicia Van Couvering (2007), em artigo publicado pela revista de cinema norte-americana Filmmaker Magazine, tenta demarcar as intenções de uma geração angustiadamente caleidoscópica:

O crítico Peary se tornou um dos primeiros defensores da obra de Bujalski depois de assistir a uma cópia em VHS de Funny Ha Ha que o diretor lhe havia enviado. Ele apoia as intenções de Swanberg e de seus pares, mas é cauteloso ao fazer comparações com o cinema de arte tradicional. "Compa- rações com Cassavetes, Rohmer, Eustache - não sei de onde alguns críticos tiram essas coisas", ele comenta. "O filme de Eustache [La Maman Et La Putain, de 1973, comparado a Mutual Appreciation pelo New York Times] é uma intensa viagem mortal. Em Cassavetes, o que está em jogo é muito maior. Acho que esses [filmes] funcionam, mesmo com tão pouca coisa em jogo, porque mesmo assim há neles grandes emoções e grandes momentos. Angústia. Ter 24 anos está longe na memória, mais ainda me identifico com a sensação de ir em festa, quando uma noite inteira não tem sentido algum" (Couvering, 2007)3.

Em uma aproximação mais acertada, talvez os códigos de Bujalski se aproximem da frieza cênica do cineasta sul-coreano Hong Sang-Soo, na qual o excesso de diálogos, ao invés de promover um aprofundamento narrativo, provoca o esvaziamento da experiência, abordando o cotidiano como uma sucessão de eventos monótonos. E, se em Sang-Soo, o trinômio conversa, mesa e cama é pontuado através de uma franqueza em relação à inabilidade de se estabelecer o afeto entre os personagens; em Bujalski, a cama está reservada apenas para uma deprimente disputa de xadrez. Tanto é assim que Joe Swanberg, também integrante do movimento mumblecore, talvez tenha realizado o filme Kissing on the Mouth (2005), contendo cenas mais explícitas de sexo, como uma resposta à frigidez de Funny Ha Ha. Para a crítica Amy Taubin" (2007), “Bujalski, cujos Funny Ha Ha e Mutual Appreciation (2005) eu já havia cobrido nestas páginas, é um escritor sutil e um diretor de atores apurado que sabe como preparar uma cena de modo que a linguagem corporal fale de maneira tão contundente quanto as palavras"5.

Em perfeita sincronicidade com a estética do filme, os diálogos e as situações reforçam a sensação de esvaziamento e indiferença. Desempregada, a protagonista migra de um emprego temporário a outro, em reflexo à transitoriedade daquelas imagens que pairam em suspensão de sentido. Suspensão essa que é reforçada pelo estado alcoólico dos personagens, que, sem exceção, bebem reiteradamente, e por uma cena bastante referencial, na qual a protagonista se depara com uma amiga imobilizada dentro de seu carro pelo excesso etílico, incapaz de racionalizar como chegou naquele estado ou para onde deveria ir. E, se por um lado, o filme se pauta por uma imobilidade que é reforçada ao longo da projeção, por outro, uma espontaneidade constrangedora trata logo de afastar da narrativa qualquer tipo de conflito. Diferente do que acontece em Quiet City (Aaron Katz, 2007), outro importante representante do mumblecore, apesar dos conflitos existirem em Funny $\mathrm{Ha} \mathrm{Ha}$, tanto os diálogos quanto o trabalho corporal dos atores operam no sentido de refutá-los, negando assim a ação.

Desta maneira, mais do que transitar entre conceitos de realismo ou simulacro, as operações presentes na decupagem de Bujalski corroboram com uma ideia autoreferencial que nega a postura clássica do cinema hollywoodiano. Ao insistir em um jogo estético autômato que tenta encobrir a ação e o conflito, o filme promove uma abertura ao real com reverberações traumáticas. A repetição de cenas que primam pela impassibilidade da falta de sentido no cotidiano, pela impossibilidade da construção dialógica e por uma insuficiência na expressão de qualquer sentimento, seja através do corpo ou da fala, trazem em sua aparência uma negação do traumático, mas que, ao mesmo tem- 
po, acenam em direção a ele. De acordo com Hal Foster, esses elementos fílmicos são menos um exercício de estilo do que um jogo incessante que busca encobrir as reais intenções do dispositivo, mas "se você entrar totalmente no jogo talvez possa expô-lo, isto é, você talvez revele o automatismo ou mesmo o autismo desse processo, por meio de seu próprio exemplo exagerado" (Foster, 2005, p. 165).

É justamente certa noção de exagero e repetição, como apontava Foster ao analisar os mecanismos de significação da Pop Art, frente à dilatação do tempo fílmico e à necessidade dos personagens de circularem em torno de suas trivialidades, muitas vezes sem sentido, que provoca no espectador um sentimento de melancolia, colocando-o em choque com o principal tema do movimento mumblecore: o esfacelamento do mundo diante de um individualismo que esvazia qualquer modo de expressão ou interação. "De alguma forma, nessas repetições, então, ocorre uma série de coisas contraditórias ao mesmo tempo: uma evasão do significado traumático e uma abertura em sua direção, uma defesa contra afetos traumáticos e sua produção" (Foster, 2005, p. 166).

Em uma das primeiras cenas do filme (Figura 1: Divulgação), semelhante ao jogo proposto por Foster, Bujalski dá início a um dispositivo narrativo que se repetirá ao longo de toda a projeção, despertando no público um incômodo diante da inércia dos personagens. Interpelada por um casal de amigos que a surpreendem caminhando e desejam saber o que ela estava fazendo naquele local, Marnie responde de maneira espontânea: "eu não sei, estou andando!". Em outro momento, quando indagado pela protagonista sobre seu final de semana, Mitchell, um amigo de trabalho que é interpretado pelo próprio Andrew Bujalski, retruca com uma frase tão evasiva quanto o tom desinteressado da pergunta: "creio que bem, não sei, não me lembro muito". Esse movimento repetitivo que tenta esconder os problemas dos personagens é o que, de fato, acaba revelando o horizonte traumático que contaminará o observador:

E essa multiplicidade dá conta do paradoxo não apenas das imagens, que são ao mesmo tempo afetivas e sem afeto, mas também dos observadores, que nem estão integrados (o que é o ideal da maior parte da estética moderna: o sujeito composto na contemplação), nem dispersos (o que é o efeito de grande parte da cultura popular: o sujeito entregue à intensidade esquizoide da mercadoria) (Foster, 2005, p. 168)

É como se a intenção de Bujalski fosse criar um fracasso ilusório que cobrasse ao observador um olhar capaz de romper com os artifícios estéticos da superfície:

No entanto, esse movimento ansioso para encobrir esse real aponta, apesar disso, para ele. O super-realismo permanece uma arte "do olho, feito desesperado pelo olhar", e o desespero aparece. Como resultado, sua ilusão fracassa não só enquanto um truque de olho, mas enquanto uma domesticação do olhar, uma proteção contra o real traumático, isto é, ela falha em não nos lembrar do real, e, nesse sentido, ela também é traumática: uma ilusão trau mática (Foster, 2005, p. 173).

Todos os personagens ou microeventos dentro da estrutura do filme parecem apontar para esta falência ilusória. É o que também está escondido entre cada uma das elipses, que, como em uma comédia farsesca, e talvez aí esteja também imbuída a ironia do título do longa-metragem, arquiteta momentos em que há a impressão de que algo assustador está prestes a acontecer - em especial, quando Marnie descobre, de maneira repentina, que seu interesse romântico havia se casado às pressas com uma antiga namorada - para, no momento seguinte, voltar a insistir na rotina apática das situações cotidianas. Nesse sentido, a abertura do real em Funny $\mathrm{Ha} \mathrm{Ha}$ se encontra justamente no modo como Bujalski apreende e domina seu dispositivo, tentando extrair o melhor possível de seus códigos e regras.

\section{O fetiche do real}

Apesar de o filme conservar um tom realista, que remonta às matrizes do neorrealismo italiano, passando pela estética tremida dos cineastas dinamarqueses do Dogma 95, o que de fato provoca a exposição do dispositivo e o fracasso ilusório é justamente a subversão destes valores. Deste modo, a ideia de real aqui, mesmo se aproximando muito daquilo que André Bazin, na década de 1940, chamava de "todo sistema de expressão, todo procedimento de relato propenso a fazer aparecer mais realidade na tela" ( Bazin, 1991, p. 244), é corrompida por uma série de elementos transgressores. Nesse sentido, Bujalski não se detém nos signos da escola italiana de cinema, acrescentando ao retrato das banalidades cotidianas um descompromisso com a duração temporal. As cenas, em sua maioria, parecem se prolongar mais do que deveriam se comparadas a um típico filme realista, mesmo que ainda assim elas conservem certa noção da imprevisibilidade típica da vida.

Tomemos como exemplo a passagem em que Marnie, após descobrir que Alex havia se casado com sua 
ex-namorada, convida o amigo Mitchell para passar o dia em sua casa com a intenção de tentar romper com a sensação de vazio instaurado pela falta de perspectivas. Na maioria dos filmes realistas, as elipses - eles jogam basquete, Mitchell tenta ensinar o jogo de xadrez a Marnie, bebem cerveja e, por fim, entregam-se a uma interminável conversa. Cenas que são sempre filmadas com uma câmera na mão que os acompanha por quase todos os cômodos da casa - progressivamente estabeleceriam uma sensação de prazer entre os amigos, explicitada pela energia imposta por uma câmera frenética em seus movimentos. No entanto, o que acontece é justamente o oposto: os cortes não acompanham o ritmo inquieto da câmera, prolongando situações que já pareciam encerradas e deflagrando, mesmo com a ausência de conflito em cena, uma sensação de repulsa que desconstrói o sentimento de amizade anteriormente estabelecido. Por fim, com uma expressão bastante aborrecida enquanto toma cerveja em um banco na varanda, só resta a Mitchell arremessar as garrafas de bebida a esmo, aceitando, assim, a falta de sentido daquele relacionamento.

Essa transgressão é menos uma ruptura com as vanguardas realistas do que a exposição da crise da arte anteriormente consolidada. Por muito tempo, o cinema moderno, consciente de uma ordem pré-estabelecida, sacrificou sua energia e criatividade em benefício de uma insistência exagerada em uma forma já esgotada. Nesse sentido, o mumblecore permite desenhar os contornos de um novo movimento estético:

[...] repensando a transgressão não como uma ruptura produzida por uma vanguarda heroica de fora da ordem simbólica, mas como uma fratura traçada por uma vanguarda estratégica, dentro da ordem.
Desse ponto de vista, a meta da vanguarda não é romper de forma absoluta com essa ordem (esse velho sonho foi abandonado), mas o de expô-lo em crise, registrando seus pontos não só de falência (breakdown), mas de passagem (breaktrough), as novas possibilidades que uma tal crise poderia abrir (Foster, 2005, p. 180).

É justamente por conservar o registro imagético em $16 \mathrm{~mm}$ que Bujalski talvez consiga expor de maneira tão evidente esta fratura. Ao preservar a película em seu processo fílmico - e o diretor é o único dentre os representantes do movimento a não aderir à tecnologia digital - salientando de maneira mais consciente que a arte evolui independente do suporte tecnológico, como ensaia Rancière ao debruçar-se sobre os estudos dos regimes de identificação da arte:

Todas essas formas de anulação ou de subversão da oposição do alto e do baixo não apenas precedem os poderes da reprodução mecânica. Eles tornam possível que esta seja mais do que a reprodução mecânica. Para que um dado modo de fazer técnico - um uso das palavras ou da câmera - seja qualificado como pertencendo à arte, é preciso primeiramente que seu tema o seja (Rancière, 2005, p. 47-48).

Tendo em vista esta noção de passagem entre os estados da arte de que trata Rancière e percebendo que Funny $\mathrm{Ha} \mathrm{Ha}$, ao mesmo tempo, em que evita os simulacros do campo ético das imagens, nas quais, cada movimento de câmera corresponderia ao ethos, ou seja, ao conjunto dos costumes e hábitos fundamentais do comportamento, também rejeita uma identificação poética dentro dos gêneros cinematográficos pré-estabelecidos, é possível posicionar o filme em um campo estético justamente por abarcar uma ideia de corpo tornado estranho a si mesmo. É como se a obra pudesse ser pensada singularmente, e tanto é assim que muitos cineastas desta geração em mosaico refutam a ideia de um movimento, através de um núcleo invariável que, negando a representatividade do simbólico, a legitimasse como uma manifestação artística:

A esse regime representativo, contrapõe-se o regime das artes que denomino estético. Estético, porque a identificação da arte, nele, não se faz mais por uma distinção no interior das maneiras de fazer, mas pela distinção de um modo de ser sensível próprio dos produtos da arte (Rancière, 2005, p. 32).

Esta arte pensada no singular, no entanto, como observa Rancière, pode apresentar alguns problemas, uma vez que, liberada da obediência a qualquer regra específica, passa a valorizar o fragmento em detrimento de qualquer hierarquia representacional ao mesmo tempo em que desconstrói o pragmatismo artístico em prol de sua constituição autônoma:

Ele afirma a absoluta singularidade da arte e destrói ao mesmo tempo todo critério pragmático dessa singularidade. Funda, a uma só vez, a autonomia da arte e a identidade de suas formas com as formas pelas quais a vida se forma a si mesma. [...] O estado estético é pura suspensão, momento em que a forma é experimentada por si mesma. O momento de formação de uma humanidade específica (Rancière, 2005, p. 34). 
Essa desierarquização, por outro lado, cria uma nova noção de verossimilhança, tornando o real uma espécie de fetiche: agora ele basta-se por si mesmo, não necessitando mais estar integrado no desenrolar dos acontecimentos. A esta ideia soma-se a caracterização da estrutura narrativa que passa a se opor ao ocioso, às notações inúteis do real, liberando o artista da preocupação com a unidade da forma. Roland Barthes, ao analisar o excesso descritivo dos romances realistas, na década de 1960, foi um dos primeiros autores a cunhar este conceito através do seu texto $O$ Efeito de Real:

A verdade desta ilusão é a seguinte: suprimido da enunciação realista a título de significado de denotação; com efeito, no preciso momento em que estes pormenores parecem notar directamente 0 real, eles não fazem mais, sem o dizerem, do que significá-lo; o barômetro de Flaubert, a portinha de Michelet não dizem afinal de conta senão isto: nós somos o real; é a categoria do real [...] que é então significada (Barthes, 2004, p. 136).

O discurso de Barthes, no entanto, embora provoque uma ruptura com a tradição do discurso aristotélico na qual a ficção deveria se guiar pela verossimilhança e referencialidade, ainda está muito atrelado a um sentimento burguês que ignora o viés social e político desta narrativa, na medida em que a democracia na descrição dos objetos também se reflete na construção dos personagens cujas vidas são igualmente insignificantes:

O efeito de realidade é um efeito de igualdade. Mas igualdade não significa somente a equivalência entre todos os objetos e sentimentos descritos pelo romancista. Não significa que todas as sensações
Figura 1: Frame de uma das primeiras cenas do filme. Fonte: Divulgação.
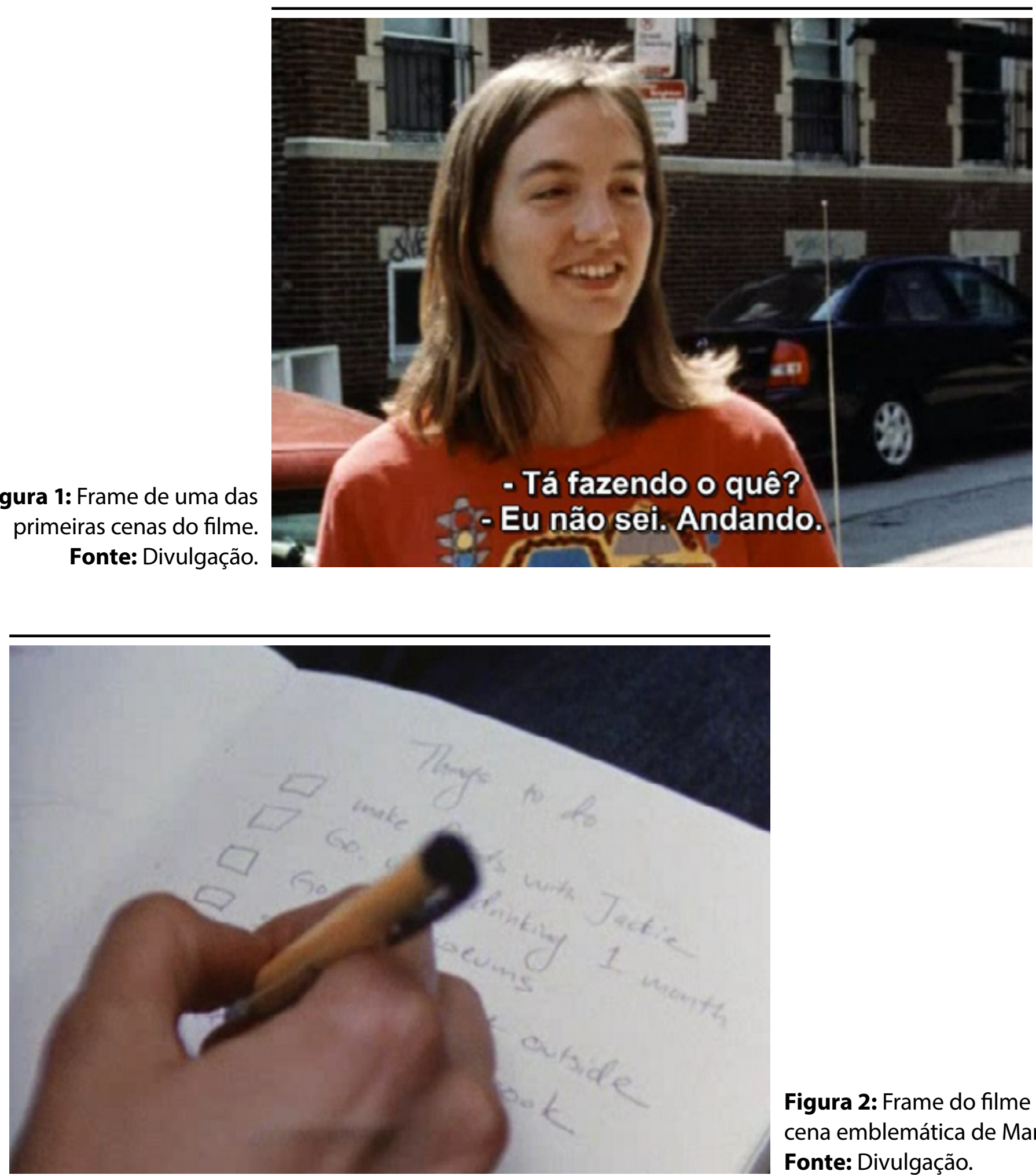

Figura 2: Frame do filme em cena emblemática de Marnie. Fonte: Divulgação.

99 PORTO ALEGRE | v. 22 | n. 37 | 2017| pp. 94-101 Sessões do Imaginário 
são equivalentes, mas que qualquer sensação pode produzir em qualquer mulher pertencente às "classes mais baixas" uma aceleração vertiginosa, fazendo-a experenciar as profundezas da paixão. Este é o amedrontador significado de "democracia" literária: qualquer um pode sentir qualquer coisa (Rancière, 2010, p. 79).

Desta maneira, considerando essa perspectiva, seja em um romance realista ou em um filme pautado pelo fluxo das imagens, a estrutura narrativa perde sua característica linear de causa e efeito, provocando uma tensão entre a ação e o excesso descritivo dos fragmentos. E se em O Vermelho e O Negro, de Stendhal, há esta desconstrução da ideia de progressão do relato quando o protagonista, depois da falência na execução de uma estratégia visando à ascensão social, resolve se entregar a um mundo de imaginação, em Funny $\mathrm{Ha} \mathrm{Ha}$, por sua vez, ao ser demitida de seu emprego, Marnie decide entregar-se ao gozo da ociosidade, permitindo-se caminhar na rua sem motivo aparente, ou mesmo esquecerse de planejar a comemoração de seu aniversário. Não por acaso, quando questionada pelo amigo Mitchell a respeito da ideia de um emprego ideal, ela escolhe a profissão de garçonete, reafirmando mais uma vez a liberdade do personagem como um espelho da liberdade artística:

O cinema não é uma arte que representa a realidade ao público. É uma forma de ação que conecta todas as formas de ação: a ação de lavar os cabelos, a ação de extrair carvão, a ação de filmar, colar e copiar, a ação de ver e etc. Esta conexão universal dos movimentos cria uma nova percepção na qual a distinção entre realidade e representação desapa- rece junto com a distinção entre arte e vida. Tudo é ação: não há "fazer nada"; ainda assim, ao mesmo tempo, a ação é libertada da sua dependência dos fins, das vontades e estratégias (Rancière, 2010, p. 79).

Nesse sentido, quando Marnie, na cena mais emblemática do filme (Figura 2: Divulgação), rascunha em um caderno uma lista de prioridades, ela manifestadamente aceita e adota esse estado do fazer nada, em que não há concessão e nem resistência, onde passar mais tempo ao ar livre não tem que, obrigatoriamente, vir antes ou depois de aprender a jogar xadrez. Em suma, a força de inércia também é força política na medida em que o personagem passa a se opor às hierarquias sociais, escolhendo desfrutar o puro sentimento da existência, do mesmo modo que a imagem aqui rejeita as amarras das hierarquias representativas.

\section{Considerações finais}

A partir da análise dos códigos presentes no processo fílmico de Andrew Bujalski em Funny $\mathrm{Ha} \mathrm{Ha}$, concluímos que sua mise-en-scène, sem conseguir estabelecer qualquer expectativa em relação à progressão narrativa, rompe com o conceito clássico de ação, ao mesmo tempo em que investe em um excesso expositivo que procura imobilizar a fluidez audiovisual, constituindo, assim, um mecanismo reiterativo que antes de provocar a domesticação do olhar do observador frente a um universo ilusório, promove uma abertura traumática em direção ao real, ou seja, à tudo aquilo que sua diegese parece querer esconder.

Primando por uma espontaneidade que é insistentemente sabotada pela dilatação do tempo e por uma digressão que evita, a todo o custo, os conflitos, o constrangimento e uma sensação de angústia surgem a partir da percepção de uma câmera cujos movimentos jamais conseguem acompanhar o processo de montagem. Os corpos já não se entendem mais, os diálogos se esvaziam em sua eloquência e a apatia caminha em direção a uma imobilidade que, ao mesmo tempo, não cede e nem resiste.

Nesse sentido, estes recursos narrativos, que vão desde uma verborragia incessante, à interpretação corporal em desajuste com as ações até o frenesi provocado pela câmera na mão, importam menos do que as metáforas que emanam deles. A presença de um objeto ou de um personagem qualquer serve apenas para comprovar a inutilidade do real e a carência de sentido da vida cotidiana. Não por acaso, o improviso é parte essencial do processo fílmico, com um elenco composto, em sua totalidade, por atores não profissionais, onde até mesmo o próprio diretor se arrisca no rascunho de uma composição que incomoda em sua naturalidade.

Desta maneira, partindo do princípio de que as artes não são autônomas e que o modo com que os elementos artísticos são dispostos é capaz de influenciar no constructo individual de quem os absorve, situamos o objeto deste artigo, considerando os regimes de identificação propostos por Jacques Rancière, dentro do regime estético da arte, tendo em vista sua singularidade e seu núcleo invariável que provocam uma suspensão da sensibilidade, justamente por insistir em uma forma que é experimentada por si mesma.

E se, por um lado, esse estatuto traz o problema de uma arte que desconhece toda uma hierarquia de gênero e temas, por outro, essas experiências libertas de qualquer enredo de causalidade reforçam a democracia de uma inércia que, ao negar o afrontamento e a 
tensão, permite que as imagens circulem livres de uma representatividade que por muito tempo sacrificou a criatividade em prol de um maneirismo em débito com as formas de uma vanguarda já esgotada.

Finalmente, longe de representar uma estética isolada ou inédita, o cinema contemporâneo tem nos mostrado que a verdadeira arte é aquela que se renova em diálogo e continuidade com as formas de vanguarda, mas que, sobretudo, ainda é capaz de acenar com novas possibilidades.

\section{Referências}

BARTHES, Roland. $O$ rumor da língua. Tradução: Mário Laranjeira. São Paulo: Cultrix, 2004.

BAZIN, Andre. $\mathbf{O}$ cinema: ensaios. Tradução: Eloísa de Araújo Ribeiro. São Paulo: Brasiliense, 1991.

COUVERING, Alicia Van. What I meant to say. Filmmaker Magazine, 2007. Disponível em: <http:// filmmakermagazine.com/archives/issues/spring2007/ features/mumblecore.php>. Acesso em: 19 ago. 2016.

FOSTER, Hal. O retorno do real. Revista Concinnitas, Rio de Janeiro, ano 6, v. 1, n. 8, p. 164-186, jul. 2005.

TAUBIN, Amy. Mumblecore: all talk? Film Comment, 2007. Disponível em: <http://www.filmcomment.com/ article/all-talk-mumblecore/>. Acesso em: 19 ago. 2016.

RANCIÈRE, Jacques. A partilha do sensível: Estética e Política. Tradução: Mônica Costa Netto. São Paulo: EXO experimental org.; Editora 34, 2005.

O efeito de realidade e a política da ficção.
Revista Novos Estudos, São Paulo, ed. 86, p. 75-90, mar. 2010.

\section{Referências audiovisuais}

BUJALSKI, Andrew. Funny ha ha. [Filme-vídeo]. Produção de Ethan Vogt, direção de Andrew Bujalski. EUA, Fox Lorber Studio, 2002. 89 min. DVD. color. son.

. Mutual appreciation. [Filme-vídeo]. Produção de Morgan Faust, Dia Sokol e Ethan Vogt, direção de Andrew Bujalski. EUA, Mutual Appreciation LLC, 2005, 109 min. DVD. P\&B. Son.

KATZ, Aaron. Quiet City. [Filme-vídeo]. Produção de Brendan McFadden e Ben Stambler, direção de Aaron Katz. EUA, Benten Films, 2007, 78 min. DVD. Color. Son.

LINKLATER, Richard. Slacker. [Filme-vídeo]. Produção e direção de Richard Linklater. EUA, Detour Film Production, 1991. $100 \mathrm{~min}$. DVD. Color. Son.

SWANBERG, Joe. Kissing on the mouth. [Filme-vídeo]. Produção e direção de Joe Swanberg. EUA, Heretic Fil$\mathrm{ms}, 2005.78 \mathrm{~min}$. DVD. color. son.

\section{Notas}

1 Doutor em Comunicação e Cultura (UFRJ). Professor titular e membro do corpo permanente do Programa de Pós-Graduação em Comunicação da Universidade Federal de Juiz de Fora (PPGCOM/UFJF - Campus Universitário, Bairro Martelos, Juiz de Fora/MG, Brasil, CEP: 36.036-330). E-mail: carlos.pernisa@uff.edu.br.

2 Mestre em Comunicação pela Universidade Federal de Juiz de Fora (PPGCOM/UFJF - Campus Universi- tário, Bairro Martelos, Juiz de Fora/MG, Brasil, CEP: 36.036-330).E-mail: talgufi@yahoo.com.br.

3 Critic Peary became an early champion of Bujalski's work after watching an early VHS copy of Funny Ha Ha the director had mailed to him. He supports the intentions of Swanberg and his peers but is wary of throwing around references to classic arthouse cinema. "Comparisons to Cassavetes, Rohmer, Eustache - I don't know where some critics get this stuff," he comments. "Eustache's movie [1973's The Mother and the Whore, linked to Mutual Appreciation by the New York Times] is an intense death trip. In Cassavetes's [films], the stakes are much higher. I think these [movies] work when they work, and even with such low stakes, because there are still big emotions and grand moments. Anguish. Being 24 is a faraway memory, but I can still relate to the feeling of going from party to party, when a whole night doesn't make any sense".

4 Amy Taubin é uma crítica de cinema norte-americana. Ela é editora contribuinte em duas revistas de cinema proeminentes: a britânica Sight \& Sound e a norte-americana Film Comment.

5 "Bujalski, whose Funny Ha Ha and Mutual Appreciation (2005) I've already covered in these pages, is a subtle writer and a fine director of actors who understands how to stage a scene so that body language speaks as strongly as words". 